\title{
MADEN ATIKLARININ SÜRDÜRÜLEBİLİR MANYETİK PİGMENT OLARAK TEKSTİL SEKTÖRÜNE GERİ KAZANIMI
}

\author{
Ecehan Aygül GÖNÜL ${ }^{1}$, Birgül BENLİ ${ }^{*}$ \\ 1 İstanbul Bilgi Üniversitesi, Uygulamalı Bilimler Yüksekokulu, Moda Tasarımı Bölümü, 34440, Türkiye, \\ ORCID No: http://orcid.org/0000-0001-6720-3740 \\ 2 İstanbul Teknik Üniversitesi, Nanobilim ve Nanomühendislik Yüksek Lisans Programı \& Maden Fakültesi, \\ Cevher Hazırlama Mühendisliği Bölümü, 34469, Maslak, Türkiye, \\ ORCID No : http://orcid.org/http://orcid.org/0000-0001-7386-5003
}

\begin{tabular}{|c|c|}
\hline Anahtar Kelimeler & Öz \\
\hline $\begin{array}{l}\text { Doğal Pigmentler } \\
\text { Demir Oksit } \\
\text { Asit Maden Dranajı } \\
\text { Geri Dönüşüm } \\
\text { Sürdürülebilir Boya }\end{array}$ & 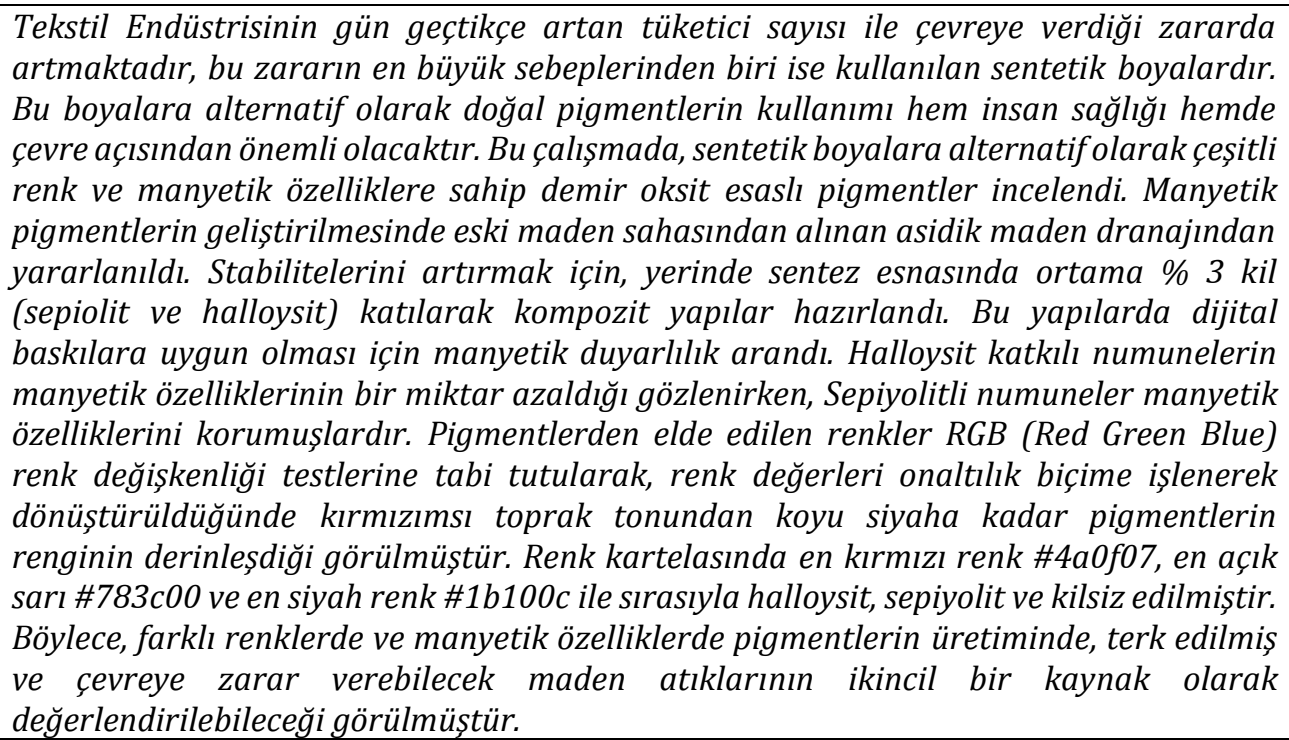 \\
\hline
\end{tabular}

\section{RECOVERY FROM MINEFIELD WASTES TO THE TEXTILE SECTOR AS} SUSTAINABLE MAGNETIC PIGMENTS

\begin{tabular}{l} 
Keywords \\
\hline Natural Pigments \\
Iron Oxides \\
Acid Mine Drainage \\
Waste Treatment \\
Sustainable Colorants
\end{tabular}

\section{Abstract}

With the increasing number of consumers of the Textile Industry day by day, one of the biggest causes of the environmental damage it creates is synthetic dyes. The use of natural pigments as an alternative to these dyes will be important for both human health and environmental use. In this study as an alternative to synthetic dyes, iron oxides with various colors and magnetic effects were investigated. In order to increase their stability, composite structures were prepared by adding 3\% clay (sepiolite and halloysite) to the in-situ synthesis solution medium. Magnetic sensitivity was sought in these structures to be suitable for digital printing. It has been observed that the magnetic properties of halloysite decreased however no such behavior was found in sepiolite-based structures. The colors obtained from the pigments were subjected to RGB (Red Green Blue) color variability tests and experimentally converted into hexadecimal form. While it was observed that the magnetic properties of the Halloysite-added samples slightly decreased, the Sepiolite samples preserved their magnetic properties. The colors obtained from the pigments were subjected to RGB (Red Green Blue) color variability

*Sorumlu yazar; e-posta : benli@itu.edu.tr

$\mathrm{Bu}$ eser, Creative Commons Attribution License (http://creativecommons.org/licenses/by/4.0/) hükümlerine göre açık erişimli bir makaledir.

This is an open access article under the terms of the Creative Commons Attribution License (http://creativecommons.org/licenses/by/4.0/). 
tests, and when the color values were converted into hexadecimal form, it was observed that the color of the pigments from reddish earth tone to dark black became deeper. In the color chart, the reddest color \# 4a0f07, the lightest yellow \# 783c00, and the blackest color \# 1b100c were halloysite, sepiolite, and clay-free, respectively. Thus, in the production of pigments with different colors and magnetic properties, it has been seen that abandoned and environmentally damaging mine wastes can be used as a secondary source.

\begin{tabular}{llll}
\hline Araştırma Makalesi & & Research Article & \\
Başvuru Tarihi & $: 01.12 .2020$ & Submission Date & $: 01.12 .2020$ \\
Kabul Tarihi & $: 05.04 .2021$ & Accepted Date & $: 05.04 .2021$ \\
\hline
\end{tabular}

\section{Giriş}

Kil ve mineral bazlı pigmentler yüzyıllardır renklendirici boyalar olarak çeşitli toplumlar tarafından kullanılmıştır. Eski ve modern sanatçılar tarafından sıklıkla toprak pigmentleri olarak adlandırılan bu renklendiriciler genellikle demir oksihidroksitten meydana gelir ve değişik miktarlarda demir $\left(\mathrm{Fe}^{+3}\right.$ veya $\mathrm{Fe}^{+2}$ ), oksijen (O) ve hidrojenden ( $\mathrm{H}$ ) oluşan doğal yapılı mineraller içerir (Cornell ve Schwertmann, 2003). Demir açısından zengin oksitler, mağara resimleri, kıyafet boyaları ve insan dövmeleri dâhil olmak üzere birçok tarih öncesi toplumlar tarafından kullanılmıştır. Günümüzde Afrika, Amerika, Güney Amerika ve Avustralya' deki pek çok kabile ve toplumda geleneksel olarak saç şekillendirme, yüz ve vücut boyamada güneșten korunma, geç ve statü göstergesi ile estetik amaçlı uygulanmaktadır.

Yeryüzündeki en yaygın minerallerden biri olan Demir oksitler, farklı kitalarda farklı medeniyetler tarafindan MÖ 75.000'den beri pigment olarak kullanılmıştır (Bu, Cizdziel ve Russ, 2013). Turuncudan kahverengiye kadar değișen bir renk skalasına sahip olan demir oksitler, tarihin bilinen en eski rengi olan Kırmızı Okre hazırlamada da kullanılmıştır. Zira Okre, içerisinde renkli demir oksit bileşiklerini içeren doğal kil yapılarından hazırlanan pigmente verilen isimdir. Tekstilde renklendirici boyalar olarak bilenen en eski kullanımı, aynı zamanda demir oksit pigmentlerinin günümüze ulaşan en eski kanıtı olan Türkiye'nin Güney Anadolu Platosu üzerinde bulunan, Çatalhöyük'teki büyük Neolitik antik kenti yerleşimde bulunmuştur (Hürriyet Daily News, 2014).

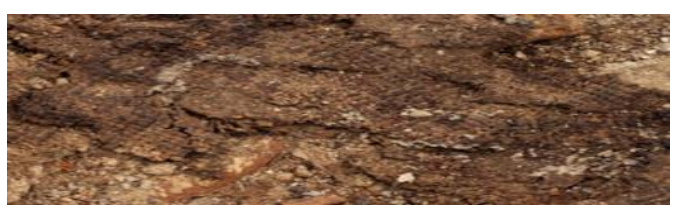

Şekil 1. Çatalhöyük'ten Kırmızı Okre Boyalı Keten Bezi (Hürriyet Daily News, 2014).

Okre ile yaygınlaşan mineral renklendiricilerin yanı sıra, doğadan bitki çiçek, kök ve meyvelerden elde edilen çok sayıda boyarmaddeler pamuk, ipek ve yün gibi doğal liflerin boyanmasında kullanılmıştır (Ayele, Tesfaye, Alemu, Limeneh ve Sithole, 2020). Buna karşın, günümüzün en popüler pigmentlerinin azo boyaları gibi sentetik pigmentler olduğunu görmekteyiz. Pek çok endüstri gibi tekstil endüstrisinde de kullanılan bu kimyasallar ciltte kolayca emilerek dermatit ve solunum yolu hastalıklarından başlayarak tümör ve meme kanserine kadar çeşitli alerjik reaksiyonlara ve sağlık etkilerine neden olabilirler (Brüschweiler ve Merlot, 2017).

Bu boyaların başka bir büyük etkisi ise çevreye verdiği hasardır, yalnızca bir tişörtün boyanması için en az 16 ile 20 litre civarında su gerekmektedir (Trusted Clothes, 2016). Kullanılan suyun tüketimi ile sentetik boyalardan çevreye yayılan olumsuz etkiler, ancak doğal boyaların kullanımı ile eko-tekstillerle engellenebileceği T.C. Çevre ve Șehircilik Bakanlığı' nın sektöre yönelik ÇED Rehberinde yer almaktadır (Solguntekin, 2014).

Boyaların yarattığı en büyük endişelerden biri de, suya giren güneş ıșığının soğurulması ve yansımasıyla beraber alglerin fotosentetik aktivitesinin azaltmasıdır. Yaşamını yitiren alglerin iskeletleri dibe çökerek, dip kayaçlarına karışmaktadır. Canlılara besin sağlayan alglerin zarar görmesi besin zincirinin bozulmasına yol açarak, su kaynaklarındaki ve çevresindeki her organizmayı etkilemektedir (Cai, Liang, Ning, Lai ve Li, 2020).

Boyalar tekstil endüstrisinde giderek artan bir çevresel sorun olduğu kadar madencilik alanında Asit Madeni Drenajı (AMD) da gün geçtikçe artan bir problemdir. Gerek üretim esnasında ve gerekse kontrolsüz bir maden atık sahasında pirit $\left(\mathrm{FeS}_{2}\right)$ gibi sülfürlü mineraller suyla ve oksijenle temasta kalabilir, bu durumda ise oksidasyon ve hidroliz reaksiyonları sonucunda sülfürik asit $\left(\mathrm{H}_{2} \mathrm{SO}_{4}\right)$ ve serbest hidrojen iyonları $\left(\mathrm{H}^{+}\right)$üreterek suyu asitleştirebilir. $\mathrm{Bu}$ asidik maden suları temas ettiği her kayacı çözerek geçtiği formasyonların yapısına bağlı olarak ağır metal içeriği yüksek drenaj çözeltilerini oluşumuna yol açarlar. Drenaj çözeltileriyle ilişkili yüksek pH ve yüksek metal konsantrasyonlarının kombinasyonu, ekosistemler ve özellikle su kaynakları üzerinde ciddi toksikolojik etkilere sahip olmaktadır (Vélez-Pérez ve diğ., 2020).

Türkiye, demir açısından zengin oksitlerin bulunabileceği büyük kömür rezervlerine ev sahipliği 
yapmaktadır. Bu küçük ve orta ölçekli madencilik faaliyetlerinden bazıları üretimi durdurmuş ve terk edilmiștir. Uygun rehabilitasyon olmadan bu alanlarda büyük delikler ve bozulmalar gelişmiştir ve oluşmuş asidik sızıntının sulara boşalması zamanla yüksek metal konsantrasyonları biriktirmiştir. Şekil 2' de ülkemizde bu şekilde bozulmuş su birikintisinin görüntüsü farklı açllardan verilmektedir (Yucel ve Baba, 2016). Bu birikintiler ve göletlerden alıcı ortamlara ulaşarak yüzey ve yeraltı sularını kirletebilecek ciddi bir kirlilik kaynağıdır.

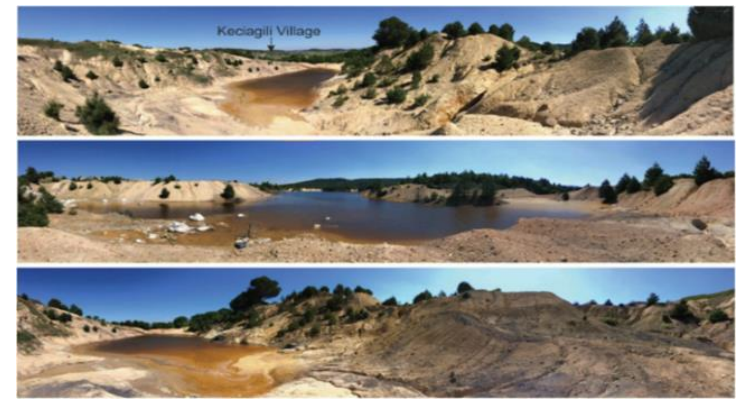

Şekil 2. Türkiye'de Kontamine Olmuş Bir Yapay Gölün Panaromik Çekimleri (Yucel ve Baba, 2016).

$\mathrm{Bu}$ çalışmada doğal killerden sepiyolit ve halloysit örnekleri kullanılarak sentetik pigmentlere alternatif pigment yapıları geliştirilmiştir. $\mathrm{Bu}$ yapıların geliştirilmesinde AMD kaynaklı çözeltilerle demir oksitler sentezlenmiş ve kil yapıları katkılandırılarak kompozit yapılar oluşturulmuştur. Oluşturulan pigmentlerle ulaşılan renkler ise RGB (Red Green Blue) renk çizergeleri üzerinden gösterilerek renk kartelası çlkarılarak sunulmuştur.

\section{Bilimsel Yazın Taraması}

Literatürde demir oksitlerin pigment olarak uygulanmasına yönelik araștırmalar mevcuttur. Ishimitsu (1969) ve $\mathrm{He}$ ve diğ. (2010) manyetize kavurma tekniği ile pirit cüruflarından demir oksit konsantresi hazırlaşmışlardır. $\mathrm{Bu}$ ulaşılan konsatrelerden demir oksit pigmentleri elde etmişlerdir. Das, Prakash, Reddy ve Misra (2007) ve Legodi ve Waal (2007) de demir oksitlerden pigment üretmişlerdir. Zheng, Chen ve Huang (2006) demir oksit pigmentleri ile farklı renk skalaları elde edebilmiştir, bu renk skalalarını elde edebilmek için yine pirit cürufları yani metalurji atıklarını kullanmıștır. Guidice (2000) demir oksit pigmentlerinin özellikle antikorozif bariyer kaplamalarda manyetik malzeme ve koruyucu kaplama olarak kullanılabileceğini öne sürmüştür. Zheng ve Liu (2011) bu pigmentlerin ekonomik ve çevresel olarak kabul edilebilir standartlarda olduğunu başarı ile göstermiştir.
Günümüzde demir oksit pigment pazarı, milyonlarca ton civarındadır ve global inorganik pigment tüketiminin yarısından fazlasını oluşturmaktadır (MM Ltd, 2020). Kırmızı, sarı ve siyah demir oksit pigmentleri, kimyasal stabiliteleri ve düşük maliyetleri ile dikkat çekici bir inorganik pigment sınıfıdır (ilter, 2015). Bu pigmentlerin ışık emme verimini azaltması ve dolayısı ile pigmentlerin ışık altında yaşlanmasını engellemesi onları dış mekan uygulamaları ve kaplamalarda cazip kılmaktadır (Butylina, Martikka ve Karki, 2015).

Demir oksit pigmentlerini sentetik pigmentlerden daha cazip kılan etkenlerin başında, sentetik pigmentlere göre daha basit kimyasal reaksiyonlarda ve oksidasyonla var olması ve doğal olarak topraktan elde edilmesidir. Buna karşılık olarak çoğu sentetik boya petrokimyasallardan ve kömür katranlarından elde edilmektedir. Demir oksitler genellikle düşük akut toksisiteye sahip güvenli gıda pigmentleri olarak kabul edilir. JECFA (Birleşmiş Milletler Gıda ve Tarım Örgütü (FAO) ve Dünya Sağlık Örgütü (WHO) tarafından ortaklaşa yönetilen uluslararası bir bilimsel uzman komitesi), kabul edilebilir günlük demir oksit alımını 0,5 mg / kg vücut ağırlığı / gün olarak belirlemiştir (JECFA, 1980). Buna kıyasla sentetik pigmentler yutmaya güvenli değildir.

Metal tabanlı yapılandırılmış nanopartiküller, manyetik özelliğe sahip sıfır boyutlu inorganik malzemelerdir. Metallerin işlenemez, ağırlığı fazla, maliyeti yüksek olmasına rağmen manyetik nanopartiküllerin ise kolayca manupüle edilebilir ve șekillendirilebilir olduğu, üretilen kumaşların dikilebilir ve katlanabilirliği ile kanıtlanmıştır (Shahidi, 2021). Bu nanopartiküller, tekstil fiberleriyle biraraya getirildiklerinde ister kaplanabilirler, istenirse nanokompozit matrisi içinde yapıya katkılandırı-labilirler, böylece elektrospun nanofiberler yani dokumasız tekstiller gibi 3 boyutlu yapıların yanı sıra özel makas veya katlanacak şekilde kolayca manipüle edilebilir ve şekillendirilebilir.

Demir yapılarla (Şekil 3) pek çok tekstil kumaşını hazırlamak mümkündür. Manyetik tekstiller hazırlamanın bir diğer yolu ise 3D yazıcılarla baskı ve ferromanyetik filamanlarla yapılabilir. Kullanılan manyetik tozun kumaşın performasını etkilemediğini, ancak kumaşın aşınma kabiliyeti üzerinde önemli etkisinin olduğunu söyleyebiliriz (Ehrmann ve Blachowicz, 2016). 


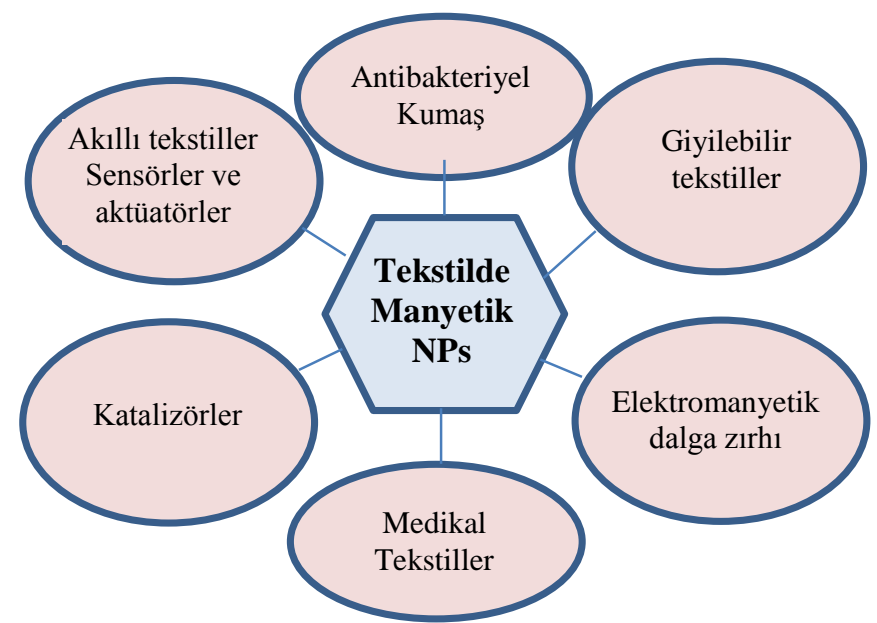

Şekil 3. Su Arıtımı Dışında Tekstil Sektöründe Nanopartiküller (NPs)

\section{Yöntem}

\subsection{Materyal}

Doğal killerden Sepiyolit ve Halloysit örnekleri Türkiye'den Tolsa, Ltd. ve ESAN Ltd.' den temin edilmiştir. Hidrate magnezyum silikat olan sepiyolit, $\mathrm{Si}_{12} \mathrm{Mg}_{8} \mathrm{O}_{30}(\mathrm{OH})_{4}\left(\mathrm{OH}_{2}\right)_{4} \cdot 8 \mathrm{H}_{2} \mathrm{O}$ formülüne sahip iken, halloysit ise $\mathrm{Al}_{2} \mathrm{Si}_{2} \mathrm{O}_{5}(\mathrm{OH})_{4}$ formülünde alüminasilikat yapılardır. Her ikisi de fiber yapılı doğal killer olup, öncelikle laboratuvar ortamında kademeli proseslere tabi tutularak saflaştırılarak zenginleştirildi. Dolgu malzemesi olarak bu killerden hazırlanan modifiye kil yapıları kullanıldı.

Demir bazl sentetik konsantreler, demir bazlı AMD çözeltisi, demir sülfat heptahidrat ve demir klorür hekzahidrat tuzlarından $\left(\mathrm{FeCl}_{3} .6 \mathrm{H}_{2} \mathrm{O}\right.$ ve $\left.\mathrm{FeSO}_{4} .7 \mathrm{H}_{2} \mathrm{O}\right)$ hazırlandı. Eski terk edilmiş maden sahasından alınan AMD çözeltisi ile karıştırılmıştır.

$\mathrm{FeCl}_{3} .6 \mathrm{H}_{2} \mathrm{O}, \mathrm{FeSO}_{4} .7 \mathrm{H}_{2} \mathrm{O}, \mathrm{NaOH}$ ve $\mathrm{NH}_{4} \mathrm{OH}$ gibi analitik saflıkta kimyasallar ve tüm çalışma boyunca çift distille su kullanıldı.

Bu çalışmada araştırma ve yayın etiğine uyulmuştur.

\subsection{Modifiye kil yapılarının hazırlanması}

Ayrı ayrı saf su ile yıkanıp kurutulmuş killerin ileri zenginleştirilmesinde, önceki bir çalışmadan (Benli, 2014) yararlanılmıştır. Kısaca killere uygulanan kademeli saflaştırma yöntemi şöyledir; yüksek hızlı bir karıștırıcı yardımıyla \%3 ağırlıkça katı oranında, suda yaklaşık 12.000 rpm'de 2 dakika boyunca karıștırma ardından, minimum 2.600 rpm'de santrifüjleme sonrasında çökelmiş yapıların süzülmesi ve üst kısmın yeniden hacmi kadar su ilavesiyle üstteki prosedürün tekrarlanması, kademeli karıștırma, santrifüjle çöktürme, sedimentasyon, ve ayırma işlemleri sonunda ele geçen yapıların $80^{\circ} \mathrm{C}$ 'de 12 saat boyunca kurutması sağlandl.

\subsection{Demir oksit sentezi}

$\mathrm{Fe}_{3} \mathrm{O}_{4}$ 'ün hidrotermal sentezi için, stokiometrik olarak hesaben yarı yarıya AMD çözeltisi ve sırasıyla ferrik iyon ve demir iyonu demir kaynağı olarak kullanıldı. $\mathrm{Fe}_{3} \mathrm{O}_{4}$ sentezi için $\mathrm{Fe}^{+3} / \mathrm{Fe}^{+2}$ molar oranı bir olarak tutuldu. Tipik sentezde, ferrik ve ferröz iyon kaynakları $100 \mathrm{~mL}$ deiyonize su içinde çözüldü. Bir termokulp kontrollü manyetik karıştırıcı yardımıyla sabit $60^{\circ} \mathrm{C}$ ' sıcaklıkta ve sabit hızlı karıştırma altında çözelti içine 37,5 mL NaOH (1N) damlalık yardımıyla damlatıldı. Daha sonra 37,5 $\mathrm{mL} \mathrm{NaOH}(5 \mathrm{~N})$ solüsyona yavaşça eklendi ve iki saat karıştırmaya devam edildi. Bu yöntem düşük temp-syn ve 60C kodlu olarak adlandırıldı. Bu solüsyonun üçte biri daha sonraki renk analizinde kullanılmak üzere buzdolabında $+4{ }^{\circ} \mathrm{C}$ sıcaklıkta muhafaza edildi. Geri kalan çözeltiden yüksek sıcaklıkta demir oksit üretimine geçildi. Çözelti bir Teflon astarlı otoklava yerleştirildi. Otoklavlanan çözelti 24 saat $200{ }^{\circ} \mathrm{C}$ 'de etüvde bekletilmiş ve 200C kodu olarak tanımlandı.

Manyetik özellikleri iyileştirmek için ise ortama $\mathrm{NH}_{4} \mathrm{OH}$ eklendi. Bu yöntemde, ferrik ve ferröz iyon kaynakları, 60 dakika boyunca $40{ }^{\circ} \mathrm{C}$ 'de sabit karıștırma altında 150 $\mathrm{mL}$ deiyonize suda ayrı ayrı çözüldü. Bir araya getirilen demir çözeltilerine $30 \mathrm{~mL} \quad \mathrm{NH}_{4} \mathrm{OH}$ (\% 26 ağırlıkça) damlalıkla 1 saat boyunca damlatılarak, ardından da karıştırma şartlarında 2 saat boyunca $60{ }^{\circ} \mathrm{C}$ sabit sicaklıkta tutuldu.

Sentezlenen siyah çökeltiler, çözeltiden bir mıknatıs ile toplandı ve birkaç kez damıtılmış su ile yıkandı ve gece boyunca $200^{\circ} \mathrm{C}$ 'de ve ardından 2 saat boyunca $600^{\circ} \mathrm{C}$ 'de kurutuldu.

\subsection{Kil ilaveli demir oksidin yerinde sentezi}

Demir oksit sentezi yöntemlerine benzer olarak, $\mathrm{NaOH}$ veya $\mathrm{NH}_{4} \mathrm{OH}$ damlatmadan sadece kil ilavesi yapılarak kompozit partiküller hazırlandı. Ferrik klorür çözeltisinin hazırlama aşamasında karıştırma ortamına saflaştırılmış doğal kilden hazırlanan modifiye killer (sepiyolit veya halloysit) eklendi. Eşit kütle oranları hesaplandı ve nihayetinde, $\mathrm{NaOH}$ yönteminde, 7,5 g kil, $\mathrm{NH}_{4} \mathrm{OH}$ yönteminde ise $3 \mathrm{~g}$ kil ilave edildi.

\subsection{Renk Değişkenliği Testleri}

Renk değișkenliği testleri standart RGB değerleri kullanılarak değerlendirildi. RGB renk modeli, renkli görüntü üretme teknolojisinde ağırlıklı olarak televizyonlar ve bilgisayarlar gibi elektronik sistemlerde kullanılır. Standart RGB değerleri sayesinde üç ana renk kullanılarak, geliştirilen renk modeli sayesinde, boyalar veya fosforlar gibi renk öğeleri ve bunların tepkileri standardize edildi, böylece üreticiden 
üreticiye ve hatta bazen aynı cihazda farklılık gösteren renk bileşenlerinin tamamen cihazdan bağımsız olarak algılaması sağlandı.

Testler için 12 megapiksel, f/1.8 kamera kullanıldı ve örneklerin görüntüleri uygulamadan 24 saat sonra çekildi. Resimler daha sonra, görüntü işleme yazılımı yardımıyla RGB değerleri onaltılık biçime işlenerek dönüştürüldü.

\subsection{Manyetik duyarlılık Testleri}

Çalışmada, düşük ve yüksek manyetik duyarlılığı test etmede, 9.000 ve 22.000 Gauss çekim kuvvetlerinde 32 $\mathrm{cm}$ çaplı ve kulplu, çubuk mıknatıslar kullanıldı. Numune üzerine değdirilerek, duyarlılık tespit edildi. Şekil 4.b ve 4.d' de mıknatıslar ve duyarlı taneler görülmektedir.

\section{Bulgular}

AMD ilaveli demir çözeltilerinden yaş ayırma işlemi ve demir oksit pigmentlerinin kurutma sonrası üretim aşamaları Şekil 4'de görülebilir. Sentezlenen demir oksit pigmentlerinde manyetik hassasiyet aranmıștır. Zira söz konusu manyetik pigmentle boyanmış kumaşlardan hazırlanan manyetik hassasiyeti yüksek yapılar, güvenlik, tekstil, sanat ve mimarlık endüstrilerinde birçok avantajla çalışılabilir. Bu pigmentlerle boyanan tekstiller, insanların her gün kullandığı elektrikli cihazlara kolayca dahil edilebilen yüksek teknoloji ürünü manyetik kumaşlar olarak işlev görebilir. Manyetik pigmentler, fotokopi ve lazer yazıcılarda toner pigmentleri olarak kullanılabilir ve banknotların yanı sıra tekstillerin basılması gibi özel baskılarda uygulama alanı bulabilir (Pfaff, 2017). Susuz baskı teknolojileri, tekstil boyamada giderek yaygınlaşan çevreci uygulama olarak eko-tekstillerde ve/veya tekstil endüstrisinde teşvik edilen uygulamaların başında gelmektedir.

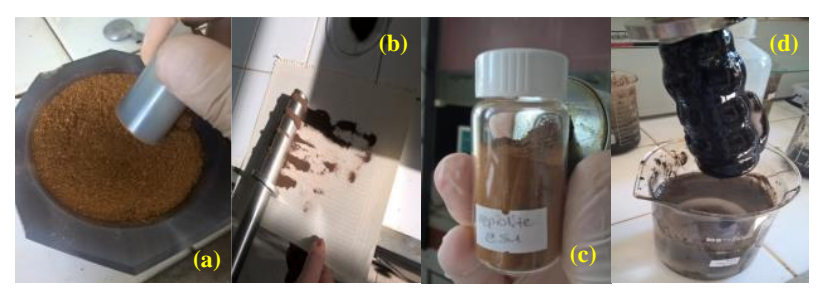

Şekil 4. (a) Pigmentin Öğütülmesi, (b) Mıknatıs Çubukla Manyetik Özelliklerinin ögütme Sonrası Kontrol Edilmesi, (c) Kurutulmuş Pigment ve (d) Kurutma Öncesi Mıknatıs Çubuk Kullanılarak Demir Oksidin Çözeltiden Ayrılması

Manyetik özellikler iki farklı biri yüksek biri düşük hassasiyetli olmak üzere mıknatıslar ile test edilmiş ve bulgular Tablo 1'de verilmiştir. Sonuçlar kil içermeyen demir oksit ile karşılaştırılmıştır. Fe-oksitlerin homojenliklerinin arttırılması ve ince tane boyutunun eldesi için öğütülmesi ardından 200 mesh $(74 \mu \mathrm{m})$ elekten geçirilmiş ve manyetik duyarlılıklarının devam ettiği görülmüştür.

Tablo 1

Sentezlenmiş Fe-kil Pigmentlerinin Manyetik Duyarlılık Testi

\begin{tabular}{lcc}
\hline \multicolumn{1}{c}{ Örnek } & Yüksek & Alçak \\
\hline Fe-NPs & + & + \\
Fe-Hal & + & + \\
Fe-Sep & + & + \\
Fe-Hal, $200^{\circ} \mathrm{C}$ & + & + \\
Fe-Sep, $200^{\circ} \mathrm{C}$ & + & + \\
Fe-Hal, $600^{\circ} \mathrm{C}$ & + & + \\
Fe-Sep, $600^{\circ} \mathrm{C}$ & + & - \\
Fe-Hal, amonyaklı, $200^{\circ} \mathrm{C}$ & - & - \\
Fe-Sep, amonyakl, $200^{\circ} \mathrm{C}$ & - & - \\
Fe-Hal, amonyakl, $600^{\circ} \mathrm{C}$ & + & - \\
Fe-Sep, amonyakl, $600^{\circ} \mathrm{C}$ & + & - \\
\hline
\end{tabular}

Sepiyolit karışık pigmentler manyetik stabilitelerini korurken, halloysit ile karışımlar düşük manyetik özelliklerdeki mıknatıslara karşı manyetik hassasiyet belirtisi göstermemiştir. Bunun nedeni, özel adsorban özellikleri veren, lif yönünde içi boş bir kanala sahip, sepiolitin yapısından kaynaklanmaktadır (Benli, Du ve Çelik, 2012). Ayrıca, saflaştırma kademesinde modifiye kil hazırlama işlemlerine tabi tutulmuş doğal yapılar olduğu unutulmamalıdır. Ülkemizin dünyanın en önemli sepiyolit rezervlerine sahip olduğu düşünülürse, çalışmanın neticesinde ulaşılan bulgunun önemi daha anlaşlacaktır.

Kumaşlardaki manyetik hassasiyet güvenlik, tekstil, sanat ve mimari endüstrilerinde birçok avantaj sağlayacaktır. Demir oksitten manyetik pigment üretiminin genel bir görünümü Şekil 5 ' teki gibidir. Görüldüğü gibi tamamen indirgenme sonrasında, metalik demir yapıları yanı sıra kısmı oksidasyonla üç değerlikli demir nanoyapıları sentezlenebilir. Uygulanabilecek yüzey işlemleri ve nihai nanoyapıların eldesinde, üretim yöntemlerinin önemli olduğu görülmektedir. Halloysit ve sepiyolit yapılarından farklı duyarlılıkta pigmentlerin eldesi ortama ilave edilen kil yapısına bağlı olarak değişmiştir. Manyetik duyarlılığı yüksek yapılarla metalik Fe nanopartikülleri oluşurken, 
bazı amonyakla işlem gören kil kompozitlerde kısmı indirgenmenin neticesinde manyetik duyarlılık düşmektedir.

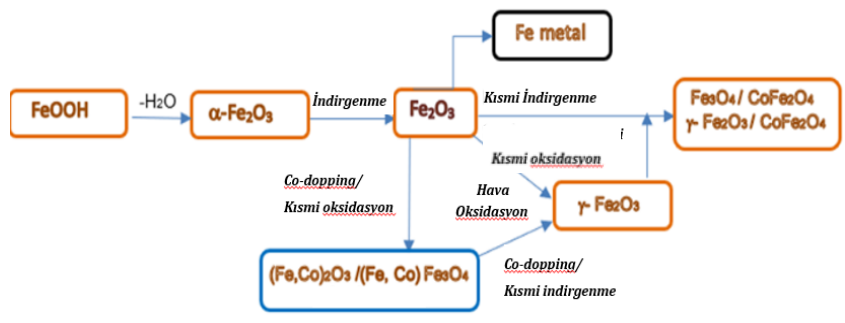

Şekil 5. Demir Oksitten Manyetik Pigmentlerin Üretimi

Düșük manyetik özelliklere sahip pigmentler, RGB Renk Şeması ve Onaltılık sayılara göre daha yüksek Chroma kahverengi renklerin elde edilebileceği görülmüştür. Demir oksit seviyeleri arttıkça ve renk kırmızımsı toprak tonundan koyu siyaha değiştikçe pigmentlerin rengi daha da derinleşmiştir, bu renk paleti Şekil 6'da görülebilir. En koyu siyah renk, manyetik özelliklerde olduğu gibi beklenen şekli ile kil katkısız saf demir oksit partiküllerinden elde edilmiştir. Renk paletinde sarı alt tonları sepiyolit kili ile elde edilirken, halloysit tipi killerde daha kırmızı alt tonlu renkler elde edilmiştir.

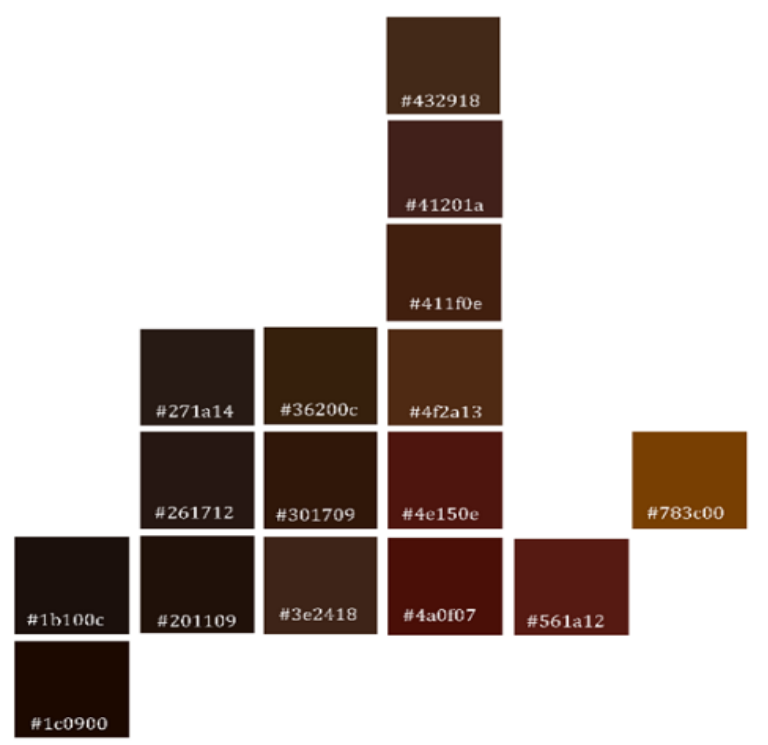

Şekil 6. Sentezlenen Fe-kil Nanopigmentlerinin RGB Değerleri ve Renk Kartelası

\section{Tartışma}

Washington Üniversitesi'ndeki araştırmacılar, parmaklarının ucuna iletken kumaş dikilmiş bir eldiven geliştirmiş, bu araştırmacılar, bir cebe gömülü bir akıllı telefon üzerinde hareket ederken, bir telefon aramasını cevaplamak veya duraklatmak veya müzik çalmak gibi belirli eylemleri kontrol edebilmişlerdir bu icat için kumaşa entegre edilmiş manyetik pigmentleri kullanmışlardır (Markovich, 2017).

Doğal toprak pigmentleri, her bir tasarımı benzersiz, türünün tek örneği yapan, tekrarlanmazlıkları ve renklerin tekdüze olmamaları nedeniyle bir tasarımcı için benzersiz imkânlar yaratabilir. Tekstil boyamada batik veya dikiş, baskı, şablon, batik vb. dâhil olmak üzere çeşitli yöntemler kullanılabilmekte, aynı zamanda çevreye olan duyarlılıkları sebebiyle de gündelik hayata uygun pigmentler olarak kullanılabilirler.

\section{Sonuçlar}

Günümüzde en yaygın kullanılan reklendiriciler sentetik pigmentlerdir, bu pigmentlerin oluşturdukları boyalar çevreye ve insan sağlığına pek çok zararlı etkiler göstermektedir. Bu yüzden sağlığa ve çevreye duyarlı doğal pigmentlerin önemi gün geçtikçe artmaktadır. Aynı zamanda çoğunlukla terk edilmiş kömür madenlerinden meydana gelen asit maden drenajlarıda ekolojik endişe yaratmaktadır. AMD’lerin ikincil bir kaynak olarak değerlendirilmeleri hem azaltmak hem de ortamı rehabilite etme amacı ile önemlidir. Bu yüzden çalışmamızda demir kaynağı olarak AMD çözeltisinden yararlanılmış, bu çözeltinin stabilitesini artırmak için halloysit ve sepiyolit killerinden yararlanılarak doğal inorganik pigmentler elde edilmiştir.

Çalışmalarda kullanılan sepiyolit ve halloysit doğal kil yapıları olup, öncelikle saflaștırma ve fiziksel dağıtmadan geçirilerek sentez ortamına katılmıştır. Özellikle dünyadaki en büyük sepiyolit rezervlerine sahip olan Türkiye için bu bulgu oldukça önemlidir.

Sentez ortamına 1:1 katılan AMD çözeltisinin verimi arttırdığı gözlenmiştir. Böylece, 200 ve $600 \mathrm{C}^{\circ}$ lerde iki farklı sıcaklıkta yapılan sentez koşulları sonrası, demir oksitler nanopartikül dispersiyonları ile saflaştırılmış sepiyolit ve halloysit kil yapıları ile stabil, dayanıklı yüksek performansl,, yüksek kroma ve renk doygunluklu pigmentler olarak üretilmiştir. Sentezlenen yapıların tekstil endüstrisinde boya olarak kullanmaya uygun olduğu görülmüştür.

İkincil bir kaynak olarak AMD’lerin kullanılabilirliği vurgulanmıș, bu sayede, demir oksitlerin renklendirici olarak kullanılması ile aksi halde terk edilmiş ve çevreye zarar verebilecek maden atıklarının da değerlendirilebileceği bu makalede vurgulanmıştır.

Aynı zamanda sentetik boyalara alternatif olmanın dışında daha üstün gösterdiği manyetik özellikler ile de baskılarda kullanılan boyalarda alternatif olabileceği vurgulanmıştır, bu özellikleri onları tekstil sektörü yanı sıra, otomotiv sektöründen elektronik baskılara dâhil birçok sektöre uygun kılmaktadır. İleride bu pigmentlerin kumaşa entegre edilmesi hakkında çalışmalar yapılmalı ve yalnızca tekstil sektöründe değil bu pigmentlerin manyetik özelliklerinin de farklı 
sanayilerde, teknolojik sistemlerde ve yenilikçi ürünlerde kullanılabileceği göz ardı edilmemelidir.

\section{Teşekkür}

Yazarlar, çalıșmanın yapılmasını İTÜ-BAP, Proje No. MGA-2018-41405 numaralı proje kapsaminda destekleyen İstanbul Teknik Üniversitesi Bilimsel Araştırma Projeleri Koordinatörlüğü' ne teşekkür ederler.

\section{Araştırmacıların katkısı}

$\mathrm{Bu}$ çalışmada, Ecehan Aygül Gönül pigment formülasyonlarının geliştirilmesi, renk değişkenliği testleri ve pigmentlerin renk skalasının çıarılması, makalenin yazımında; Birgül Benli deney tasarımlarının yapılması, numunelerin temini, makalenin genel kontrollerinin yapilması konularında katkı sağlamışlardır.

\section{Çıkar Çatışması}

Yazarlar tarafından herhangi bir çıkar çatışması beyan edilmemiștir.

\section{Kaynaklar}

Ayele, M., Tesfaye, T., Alemu, D., Limeneh, M. ve Sithole, B. (2020). Natural dyeing of cotton fabric with extracts from mango tree: A step towards sustainable dyeing. Sustainable Chemistry and Pharmacy, 17, 1-8. doi: https://doi.org/10.1016/ j.scp.2020.100293

Benli, B. (2014). Effects of humic acid release from sepiolite on the interfacial and rheological properties of alkaline dispersions. Applied Clay Science, 102, 12/2014, 1-7. doi: https://doi.org/10.1016/ j.clay.2014.10.004.

Benli, B., Du, H. ve Çelik, M.S. (2012). The anisotropic characteristics of natural fibrous sepiolite as revealed by contact angle, surface free energy, AFM and molecular dynamics simulation. Colloids and Surfaces A Physicochemical and Engineering Aspects. 408, 22-31. doi: https://doi.org/10.1016/ j.colsurfa.2012.04.018.

Brüschweiler, B.J. ve Merlot, C. (2017). Azo dyes in clothing textiles can be cleaved into a series of mutagenic aromatic amines which are not regulated yet. Regulatory Toxicology and Pharmacology, 88, 214-226. doi: https://doi.org/10.1016/ j.yrtph.2017.06.012.

Bu K., Cizdziel, J.V. ve Russ, J. (2013). The source of ironoxide pigments used in Pecos river-style rock paints.
Archaeometry, 55 (6) 1088-1100. doi: https://doi.org/10.1111/arcm.12011

Butylina, S., Martikka, O. ve Karki, T. (2015). Weathering properties of coextruded polypropylene-based composites containing inorganic pigments. Polymer Degraation and Stability, 120, 10-16. doi: https://doi.org/10.1016/j.polymdegradstab.2015.06.004

Cai, H., Liang, J., Ning, X., Lai, X. ve Li, Y. (2020). Algal toxicity induced by effluents from textile-dyeing wastewater treatment plants. Journal of Environmental Sciences, 91, 199-208. doi: https://doi.org/10.1016/j.jes.2020.01.004

Cornell, R.M. ve Schwertmann, U. (2003). The iron oxides: structure, properties, reactions, occurrences and uses. Wiley-VCH Verlag GmbH \& Co. KGaA. doi: https://doi.org/10.1080/15440478.2019.1691118

Das, B., Prakash, S., Reddy, P.S.R. ve Misra, V.N. (2007). An overview of utilization of slag and sludge from steel industries. Resources, Conservation and Recycling, $50 \quad$ (1), 40-57. doi: https://doi.org/10.1016/j.resconrec.2006.05.008

Ehrmann, A. ve Blachowicz, T. (2016). Examination of textiles with mathematical and physical methods; Chapter 3: magnetic yarn, fabrics and coatings. New York: Springer International Publishing.

He, B.H., Tian, X.K., Sun, Y., Yang, C., Zeng, Y.L., Wang, Y.X., ... Pi. Z.B. (2010). Recovery of iron oxide concentrate from high-sulfur and low-grade pyrite cinder using an innovative beneficiating process. Hydrometallurgy, $\quad 104, \quad 241-246 . \quad$ doi: https://doi.org/10.1016/j.hydromet.2010.06.009

Centuries-old fabric found in Çatalhöyük. (2014). Hürriyet Daily News. Erişim adresi: https://www.hurriyetdailynews.com/centuriesold-fabric-found-in-catalhoyuk-61883

Ishimitsu, A. (1969). Process of obtaining a granular charge for the blast furnace from a pyrite cinder and iron manufacture dust or powdered iron ore, United States Patent. Erişim adresi: https://patents.google.com/patent/US3615342

İlter, M. (2015). Tekstil Üretimi ve Yardımcı Kimyasallar. TMMOB Kimya Mühendisleri Odası. İzmir. Erişim adresi: https://www.kmo.org.tr/ resimler/ekler/ae5e4a388eea976 ek.pdf

JECFA. (1980). Twenty-third report of the Joint FAO/WHO Expert Committee on Food Additives. Joint FAO/WHO Expert Committee on Food Additives, World Health Organization \& Food and Agriculture Organization of the United Nations. Evaluation of certain food additives: twenty-third report of the Joint FAO/WHO Expert Committee on Food Additives. [meeting held in Geneva from 2 to 11 
April 1979]. World Health Organization. Erişim adresi: https://apps.who.int/iris/handle/10665/41403

Legodi, M.A. ve de Waal, D. (2007). The preparation of magnetite, goethite, hematite and maghemite of pigment quality from mill scale iron waste. Dyes and Pigments, 74 (1), 161-168. doi: https://doi.org/10.1016/j.dyepig.2006.01.038

Markovich, M. (2017). A shirt that doubles as your password) UW researchers creating 'high-tech' fabrics, Komonews. Erişim adresi: https://komonews.com/news/local/uwresearchers-creating-high-tech-fabrics-that-canstore-data

MM Ltd. (2020). Inorganic Pigments Market by Pigment Type (Titanium Dioxide, Iron Oxide, Carbon Black), Application (Paints \& Coatings, Plastics, Inks). EndUse Industry (Building \& Construction, Automotive, Packaging, Textiles). Region - Global Forecast to 2024. Erişim adresi: https://www.marketsandmarkets.com/MarketReports/inorganic-pigment-market267172103.html.

Pfaff, G. (2017). Inorganic pigments. Walter de Gruyter GmbH, Berlin. doi: https://doi.org/10.1515/ $\underline{9783110484519}$

Shahidi S. (2021). Magnetic nanoparticles application in the textile industry-A review. Journal of Industrial Textiles, 50(7), 970-989. doi: https://doi.org/10.1177/1528083719851852

Solguntekin, B. (2014). Çevresel Etki Değerlendirmesi, Sektörel Rehberleri, ÇED Rehberi - Tekstil Fabrikalar. T.C. Çevre ve Şehircilik Bakanlığı Yayınları. Erişim adresi: https://www.mevzuat.gov.tr/ $\underline{\text { mevzuat? MevzuatNo=15572\&MevzuatTur=9\&Mevz }}$ $\underline{\text { uatTertip }=5}$

Trusted Clothes. (2016). "Impact of dyes" Trusted Clothes, Erişim adresi: https://www.trustedclothes.com/blog/2016/06/2 3/impact-of-dyes/

Vélez-Pérez, L.S., Ramirez-Nava, J., Hernández-Flores, G., Talavera-Mendoza, O., Escamilla-Alvarado, C., PoggiVaraldo, H.M., ... López-Díaz, J.A. (2020). Industrial acid mine drainage and municipal wastewater cotreatment by dual-chamber microbial fuel cells. International Journal of Hydrogen Energy, 45 (26), 13757-13766. doi: https://doi.org/10.1016/ j.ijhydene.2019.12.037

Yucel, D.S. ve Baba, A. (2016). Prediction of acid mine drainage generation potential of various lithologies using static tests: Etili coal mine (NW Turkey) as a case study. Environmental Monitoring and Assessment. 188, 473. doi: https://doi.org/10.1007/s10661-016-5462-5
Zheng, Y., Chen, M. ve Huang, G. (2006), Preparation of potassium iron blue from pyrite cinders. Zhongnan Daxue Xuebao (Ziran Kexue Ban)/Journal of Central South University (Science and Technology), 37 (2), 252-256. Erişim adresi: https://www.researchgate.net/publication/279710 626 Preparation of potassium iron blue from pyri te cinders

Zheng, Y. ve Liu, Z. (2011). Preparation of monodispersed micaceous iron oxide pigment from pyrite cinders, Powder Technology, 207 (1-3), 335342. doi: https://doi.org/10.1016/j.powtec.2010.11.015 